\title{
Aplicação do Sistema de Indicadores de Sustentabilidade Pressão-Estado-Impacto-Resposta (PEIR) no Município de Nazarezinho-PB: enfoque no estado dos resíduos sólidos
}

\section{Anderson Maciel Soares ${ }^{1}$, José Deomar de Souza Barros², Danielly de Sousa Bezerra ${ }^{1}$}

${ }^{1}$ Curso de Licenciatura em Ciências Biológicas. Unidade Acadêmica de Ciências Exatas e da Natureza (UACEN). Universidade Federal de Campina Grande (UFCG). Grupo de Pesquisa Ambiental para o Desenvolvimento do Semiárido (GPA).

${ }^{2}$ Universidade Federal de Campina Grande (UFCG). Grupo de Pesquisa Ambiental para o Desenvolvimento do Semiárido (GPA). E-mail: deomarbarros@gmail.com.

Resumo. O acúmulo de resíduos sólidos em locais inadequados pode gerar risco a saúde, dessa maneira, é preciso administrá-lo de forma lógica para que a sua gestão aconteça de modo participativo, procurando a partir de ações sustentáveis com vistas à preservação dos recursos naturais, e o bem-estar humano. Assim, a presente pesquisa teve como objetivo aplicar o Sistema de Indicador Pressão-Estado-Impacto-Resposta (PEIR), com ênfase no estado dos resíduos sólidos no Município de Nazarezinho-PB. Para isso, foi utilizado o Modelo PEIR desenvolvido pela Organização para a Cooperação e Desenvolvimento Econômico (OCDE) e Programa das Nações Unidas para o Meio Ambiente (PNUMA), com realização de entrevistas a atores sociais que atuam diretamente ou de forma indireta na problemática dos resíduos sólidos no município. Foram empregados nove indicadores no estado, sendo classificados como favoráveis ou desfavoráveis, do ponto de vista sustentável. Como resultado, foi constatado que a dimensão estado foram selecionados nove indicadores dos quais todos foram avaliados como DESFAVORÁVEIS do ponto de vista da sustentabilidade, por não apresentarem resultados que se adéquem aos requisitos necessários para um município conciliar o desenvolvimento econômico e conservação do meio ambiente.

Palavras-chave: Resíduos sólidos; Gestão ambiental; Indicadores de sustentabilidade.

\begin{abstract}
Application of the driving forces-pressure-state-impactresponse framework of sustainability indicators in the Municipality of Nazarezinho, State of Paraíba, Brazil: focus on the state of solid waste. The accumulation of solid waste in inappropriate places can pose a risk to health. It is therefore necessary to administrate this problem in a logical manner so that management occurs in a participatory way, seeking sustainable actions aimed at the preservation of natural resources and human wellbeing. The aim of the present study was to apply sustainability indicators with an emphasis on the state of solid waste in the Municipality of Nazarezinho in the State of Paraíba, Brazil. For such, the driving
\end{abstract}

Recebido:

20/10/2017

Aceito:

08/11/2017

Publicado:

31/12/2017

Acesso Aberto

Artigo completo

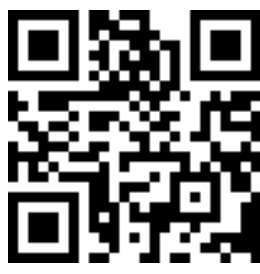

ORCID

(ㄱ) 0000-0001-9357-1563

Anderson Maciel Soares

(1) 0000-0003-3785-9823

José Deomar de Souza

Barros

D 0000-0002-7905-3994

Danielly de Sousa

Bezerra 
forces-pressure-state-impact-response framework developed by the Organization for Economic Cooperation and Development and the United Nations Environmental Program. Interviews were held with social actors who work directly or indirectly on the problem of solid waste in the municipality. Nine state indicators were employed and classified as either favorable or unfavorable from the standpoint of sustainability. As the indicators did not meet the necessary requirements for a municipality to reconcile economic development with the preservation of the environment, all indicators in the state domain were classified as UNFAVORABLE.

Keywords: Solid waste; Environmental management; Sustainability indicators.

\section{Introdução}

A consciência ambiental é uma das questões mais trabalhadas globalmente, sendo indispensável para o homem contemporâneo que desenvolve suas atividades vinculadas a natureza, sem esquecer que é um ser integrante dela. A responsabilidade com o meio ambiente é uma forma de diminuição do processo de degradação, e uma tomada de consciência com a sociedade, uma vez que os danos causados pelo o homem é resultado do desenvolvimento perante o consumismo e consequentemente ao desperdício (Batista, 2009; Silva, 2010).

A preservação dos recursos naturais representa o desenvolvimento econômico e social e é voltado para a qualidade ambiental de uma localidade, colaborando para uma ação efetivada ao considerar as informações existentes relevantes. A sustentabilidade aparece como uma explicação ou auxilio de políticas direcionadas para a problemática ambiental, atuando no funcionamento de planejamentos e medidas que forneçam informação à população (Silva e Cândido, 2012; Silva et al., 2012).

Os resíduos sólidos urbanos são os resíduos que estão mais relacionados com o desenvolvimento, já que a produção é um indicador de consumo, e este por outro lado é mais frequente nas sociedades de maior poder aquisitivo. Assim, podendo ter várias possibilidades de destino, mas o mais comum são os lixões a céu aberto, devido ao não investimento dos gestores públicos no destino final dos resíduos produzidos, o lixo é transportado e depositado geralmente em um terreno baldio ficando exposto a todo tipo de influências (Silva, 2010; Gouveia, 2012).

As preocupações, em caráter global, pela redução do desequilíbrio ambiental, impulsionam a criação de indicadores de sustentabilidade que facilitam o reconhecimento do desenvolvimento sustentável. São considerados como ferramentas essenciais para a informação e comunicação de atividades relacionadas à sustentabilidade, uma vez que apresentam um número significativo de dimensões visíveis ao direcionamento dos focos para um sistema sustentável (Malheiros et al., 2012; Silva e Cândido, 2012).

Assim a presente pesquisa teve por objetivo aplicar o sistema de indicador Pressão-Estado-Impacto-Resposta (PEIR), com ênfase no estado dos resíduos sólidos em Nazarezinho-PB.

\section{Metodologia}

A presente pesquisa foi realizada no Município de Nazarezinho, Estado da Paraíba, no período de $1^{\circ}$ de março de 2017 a 31 de julho de 2017.

\section{Caracterização da área de estudo}

O Município de Nazarezinho está localizado ao oeste da Depressão do Alto Sertão do Estado da Paraíba (Figura 1), em uma altitude de $272 \mathrm{~m}$, distando $470 \mathrm{~km}$ da Capital João Pessoa. O município apresenta cerca de 7.280 habitantes, distribuídos nas zonas urbana e rural. Possui uma área de $191,49 \mathrm{~km}^{2}$. Nazarezinho faz fronteira com 
os Municípios de Marizópolis e Sousa, ao norte; ao Sul, com Carrapateira, Aguiar e São José de Piranhas; a Oeste, com
Cajazeiras; a Noroeste, com São João do Rio do Peixe; e ao Leste, com São José da Lagoa Tapada (CPRM, 2005; IBGE, 2010).

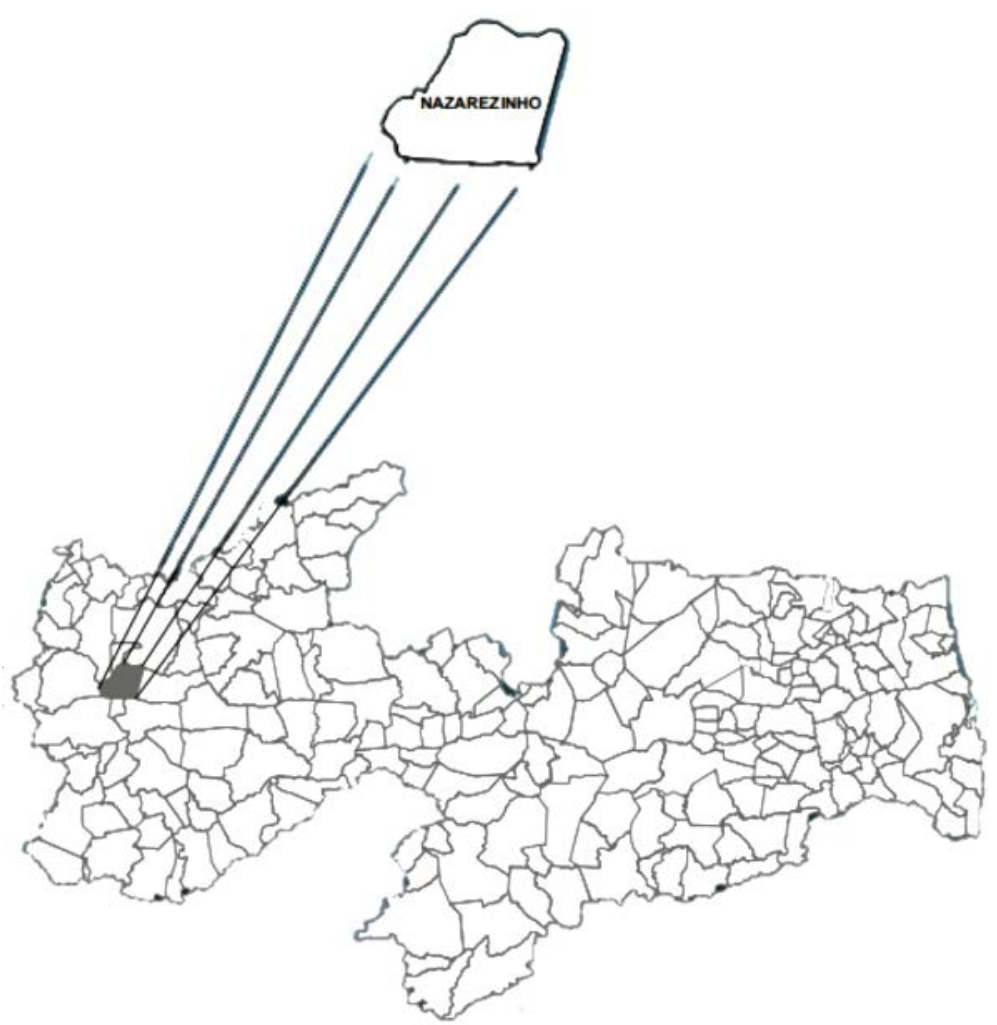

Figura 1. Localização do Município de Nazarezinho no mapa da Paraíba. Fonte. CPRM (2005).

\section{Classificação da pesquisa}

Em conformidades com Silva e Menezes (2005), do ponto de vista de sua natureza trata-se de uma pesquisa aplicada, objetiva gerar conhecimentos com aplicação prática e dirigida à solução de problemas específicos. Envolve verdades e interesses locais. Quanto a forma de abordagem do problema, o trabalho tem caráter de uma pesquisa quali-quantitativo, ou seja, quanto aos aspectos quantitativos traduz em números as informações, para assim classificá-las e analisá-las, requerendo o uso de recursos e de técnicas estatísticas, já em relação aos aspectos qualitativos considera que há uma relação dinâmica entre o mundo real e o sujeito, isto é, um vínculo indissociável entre o mundo objetivo e a subjetividade do sujeito que não pode ser traduzido em números. $\mathrm{O}$ estudo foi caracterizado do ponto de vista da sua natureza como descritivo, pois envolve a relação de variantes com uma determinada população e outros fenômenos, envolvendo questionário, entrevista e observação sistemática. Quanto aos procedimentos técnicos, trata-se de um estudo de caso, já que envolve um estudo aprofundado e complexo sobre um ou vários objetos de maneira que se permita o seu amplo e detalhado conhecimento.

\section{Sujeitos da pesquisa}

Com relação às pessoas que compõem este estudo, foram consultados 
representantes do poder público como: prefeito, ex-prefeito, vereadores, secretários municipais, funcionários de limpeza urbana, catadores, representantes de associações e escolas, comerciantes e moradores dos bairros que compõem o município, enfim, todos os atores sociais e institucionais que atuam de forma direta ou indiretamente com a temática desse estudo.

\section{População, amostra e amostragem}

A realização desse trabalho contou com a participação da população do Município de Nazarezinho-PB, sendo a amostra composta por 44 habitantes, estes denominados de atores sociais e institucionais, com relação direta ou indireta com a problemática ambiental desta pesquisa (Tabela 1 ).

Tabela 1. Número de entrevistas junto aos atores sociais e institucionais.

\begin{tabular}{lc}
\hline Atores sociais e institucionais & Entrevistados \\
\hline Representantes do poder público & 6 \\
Moradores de bairros & 18 \\
Representantes de associações e escolas & 2 \\
Agentes de limpeza & 5 \\
Catadores & 2 \\
Comerciantes & 5 \\
Lideranças sociais (líderes religiosos e presidentes de associações comunitárias) & 6 \\
\hline Total & $\mathbf{4 4}$ \\
\hline
\end{tabular}

Fonte: Adaptado de Silva (2010) e Barros e Moreira (2017).

\section{Instrumentos de coleta de dados}

Na coleta de dados, foi utilizado levantamento bibliográfico, ocorreu aplicação de questionários e realização de entrevistas com os principais atores sociais e institucionais do Município de Nazarezinho-PB, além da observação in loco do estado provocados pelo gerenciamento inadequado dos resíduos na cidade supramencionada. A referida pesquisa foi aprovada pelo Comitê de Ética em Pesquisa (CEP), da Universidade Federal de Campina Grande, sob protocolo CAAE 64563317.8.0000.5575.

\section{Análise dos dados}

$\mathrm{Na}$ análise dos dados se utilizou a abordagem quali-quantitativa, buscando avaliar o gerenciamento de resíduos sólidos por meio do sistema de indicadores de sustentabilidade Pressão-Estado-ImpactoResposta (PEIR) no Município de Nazarezinho-PB, com enfoque no estado. Os indicadores foram avaliados utilizando-se os critérios de "favorável” ou “desfavorável” do ponto de vista da sustentabilidade, nesse sentindo, ao final da análise dos dados foi utilizado um somatório em todo o sistema de indicador, no intuito de verificar a média de indicadores que incidirão positivamente ou negativamente.

\section{Resultados e discussão}

Para realização da pesquisa foi utilizado o sistema de Indicador Pressão-Estado-Impacto-Resposta (PEIR), adaptado de Silva (2010). O Modelo PEIR desenvolvido pela Organização para a Cooperação e Desenvolvimento Econômico (OCDE) e Programa das Nações Unidas para o Meio Ambiente (PNUMA), com realização de entrevistas a atores sociais que atuam diretamente ou de forma indireta na problemática dos resíduos sólidos no município supracitado. Empregou-se 09 indicadores no estado, sendo classificados como favoráveis ou desfavoráveis, do ponto de vista da sustentabilidade. 

gases)

\section{Qualidade do ar (drenagem dos}

Como relatado por Silva (2010), em sua pesquisa no Município de Cuité-PB, os aterros sanitários são avaliados como as instalações mais apropriadas para armazenamento do lixo. Mas, necessita de um sistema de drenagem de gases, para coleta e aproveitamento do biogás (metano, gás carbônico e água), quando se refere à qualidade do ar. É um importante indicador da situação em que se encontra o meio ambiente, contribuindo para o abatimento dos gases do efeito estufa e tantos outros gases que causam problema a saúde.

O Município de Nazarezinho-PB adota o vazadouro a céu aberto como destinação final de seus resíduos, não sendo uma prática que contribua para a preservação dos recursos naturais. Por isso, nesse tipo de destinação não se observa a presença de nenhum sistema de drenagem de gases, o que permite avaliar este indicador como DESFAVORÁVEL à sustentabilidade do município.

\section{de gases)}

Qualidade do ar (aproveitamento

O aproveitamento de gases possibilita inúmeros benefícios, como diminuição dos gases poluentes e, consequentemente, menos agressões à natureza. Em seu trabalho realizado no Município de Aurora-CE, Moreira e Barros (2017) enfatiza a importância do biogás como uma alternativa de energia renovável, produzindo eletricidade, vapor e combustível. Assim, o aproveitamento dos gases produzidos torna-se uma fonte de lucro a partir de um gerenciamento de resíduos sólidos adequado, fazendo com que os impactos ao meio ambiente sejam menos frequentes.

Portanto, a partir dos dados coletados nesta pesquisa, foram estes através de entrevistas feitas a todos os 44 atores sociais, observações feitas no Município de Nazarezinho-PB e, em particular, a área de disposição, não se constatou a presença de nenhum tipo de sistema de aproveitamento de gases, o que avalia este indicador como DESFAVORÁVEL.

\section{Existência de instalações administrativas \\ De acordo com Silva (2010) e} Moreira e Barros (2017), as instalações administrativas em aterros sanitários funcionam como unidade de gerenciamento da disposição do lixo no local, servindo como ponto de atendimento para pesquisas e fiscalizações, além de fazer a vigília do material de trabalho e fornecer apoio aos encarregados por essa atividade.

Em consideração a esses aspectos, este indicador é classificado do ponto de vista da sustentabilidade como DESFAVORÁVEL devido ao município em questão não possuir aterro sanitário, o que, consequentemente, não se observa a existência de instalações administrativas no local de disposição final dos resíduos produzidos.

$\begin{array}{cccc}\begin{array}{c}\text { Existência } \\ \text { impermeabilização } \\ \text { Reunindo }\end{array} & \text { uma } & \text { base } & \text { de } \\ & & \text { série } & \text { de }\end{array}$ características que contribuem para fornecer a durabilidade e resistência dos resíduos depositados, a base de impermeabilização garante o seguro confinamento dos resíduos sólidos no aterro sanitário sem haver infiltrações ou contanto diretamente com o solo. Esse sistema impermeabilizante procura atender as necessidades existentes com custo relativamente pequeno, utilizando principalmente as geomembranas em polietileno de alta densidade (PEAD), por proporcionar segurança no seu emprego, além de possuir facilidade e rapidez na instalação (Locastro e Angelis, 2016).

Para tanto, mesmo com todas as tecnologias hoje disponíveis e ainda, com a disponibilidade de materiais de baixo custo no mercado, a implementação de bases impermeabilizantes como componente ideal para o não contato dos resíduos com o solo é raro, restringindo-se apenas aos locais que possuem aterros sanitários. Por isso, no Município de Nazarezinho-PB não se observa a existência de base de impermeabilização, já que os resíduos sólidos são destinados a um vazadouro a céu aberto, o que avalia este indicador 
como negativo (DESFAVORÁVEL) do ponto de vista da sustentabilidade.

\section{Frequência de cobertura dos resíduos sólidos}

A cobertura frequente dos resíduos é principalmente adotada onde o aterro sanitário é utilizado como destinação final do lixo, neste modo de aplicação os resíduos ficam confinados por camadas de argila. Embora, os aterros sanitários contribuam para a diminuição da exposição do lixo e menor ocupação de áreas ambientais, o processo de cobertura só deveria ser feito após a incineração correta dos resíduos para que possa diminuir o seu volume, prática essa não adotada em quase todos os aterros. A aplicação da cobertura dos resíduos nos aterros sanitários objetiva o controle de água e de ar, minimizando a circulação de líquidos lixiviados e biogás (Locastro e Angelis, 2016).

Ainda baseado nas informações de Locastro e Angelis (2016), pode-se citar a utilização do entulho gerado nas construções civis como materiais de baixo custo, comum nas zonas urbanas e de fácil utilidade na cobertura dos resíduos, diminuindo o seu contato direto com o ambiente externo. Seu emprego permite suavizar os odores gerados pelos resíduos em decomposição, e enfraquecer os vetores de doenças. Para tanto, deve-se ressaltar que a utilização de coberturas frequentes de resíduos sólidos deve ocorre em áreas que não favoreça o processo de erosão do solo, já que a circulação da água pode ajudar na exposição dos materiais confinados.

No município analisado não existe processo de cobertura dos resíduos sólidos por se tratar de um vazadouro a céu aberto, logo este indicador é avaliado como DESFAVORÁVEL à sustentabilidade.

\section{Drenagem do chorume}

O chorume é um líquido de coloração escura e odor desagradável proveniente das reações biológicas, químicas e físicas da decomposição anaeróbica de resíduos orgânicos. Em contato com água, o volume do chorume aumenta chegando a contaminar cursos de rios e lençóis freáticos. Seu alto teor de poluição está relacionado devido a sua produção não ser derivada apenas de materiais orgânicos, em que a sua exposição no vazadouro pode se aderir a produtos tóxicos como pilhas, baterias e lâmpadas fluorescentes (Lopes, 2006).

Quanto à drenagem de chorume esse processo se assemelha com as técnicas utilizadas no tratamento de esgotos, considerando importante verificar sua vazão e composição antes e depois do processo de tratamento, já que a qualidade e quantidade variam bastante de um aterro para outro, visto que a composição do lixo é diferente (Moreira e Barros, 2017). Assim, este indicador é classificado como DESFAVORÁVEL à sustentabilidade do município por não realizar nenhum processo de drenagem de chorume.

Tratamento de chorume na mesma área da unidade

De acordo com Moreira e Barros (2017), o tratamento do chorume pode ser feito em três processos: tratamento químico, tratamento por oxidação e tratamento biológico, sendo este último o mais adotado nos aterros de todo o Brasil. Nesse tipo de tratamento é necessária a existência de instalações adequadas para que o chorume possa ser tratado através da estabilização da matéria orgânica, ou seja, a redução do potencial de poluição. Esse processo assemelha-se ao de tratamento de esgotos, devido realizar praticamente as mesmas etapas, além de possuir baixo custo e ser de simples utilização.

Mesmo sendo técnicas de baixo custo e fácil utilização, o Município de Nazarezinho-PB não possui processo de tratamento de chorume, o que permite avaliar este indicador como DESFAVORÁVEL.

\section{Licenciamento ambiental}

O licenciamento ambiental para a disposição do lixo urbano em um determinado terreno é a permissão dada para uma área funcionar como ponto de recebimento dos resíduos produzidos e coletados nas ruas da cidade. Essa autorização de funcionamento possui prazo de validade definido, além de regras, 
condições, medidas de controle ambiental e restrições de acordo com a área escolhida, visando encontrar o convívio equilibrado entre a ação econômica do homem e o meio ambiente onde se insere (Brasil, 2007).

O CONSELHO NACIONAL DO MEIO AMBIENTE-CONAMA, no uso das atribuições que lhe são conferidas pelo art. $8^{\circ}$, inciso I, da Lei $\mathrm{n}^{\circ}$ 6.938, de 31 de agosto de 1981, e tendo em vista o disposto em seu Regimento Interno, e considerando que a disposição inadequada de resíduos sólidos constitui ameaça à saúde pública e agrava a degradação ambiental, comprometendo a qualidade de vida das populações; considerando as dificuldades que os municípios de pequeno porte enfrentam na implantação e operação de aterro sanitário de resíduos sólidos, para atendimento às exigências do processo de licenciamento ambiental; considerando que a implantação de aterro sanitário de resíduos sólidos urbanos deve ser precedida de Licenciamento Ambiental por órgão ambiental competente nos termos de legislação vigente; considerando o disposto no artigo 12 da Resolução CONAMA n ${ }^{\circ}$ 237, de 19 de dezembro de 1997, que possibilita a adoção de procedimentos simplificados, observados a natureza, características e peculiaridades da atividade ou empreendimento.

De acordo com as informações prestadas pela gestão do município, o terreno utilizado pela prefeitura como local de disposição do lixo urbano é de propriedade da prefeitura, mas não possui licenciamento ou outro tipo de permissão para o funcionamento a que se refere. Assim, no uso da metodologia PEIR este indicador é classificado como DESFAVORÁVEL à sustentabilidade do município.

Monitoramento ambiental
Nem toda atividade de
acompanhamento, planejamento e
desenvolvimento de práticas que
contribuam para a sustentabilidade de um
local pode ser chamada de monitoramento

ambiental. Este instrumento efetivo de gerenciamento quando aplicado aos resíduos sólidos urbanos permite estabelecer objetivos a serem alcançados e a partir dos resultados avaliados elencar as possibilidades de melhoras a ser implantadas. O monitoramento ainda ajuda a compreender os níveis de chorume, além de fazer uma análise comparativa da vegetação antes e depois da implementação do vazadouro na área (Besen, 2011).

Deste modo, na Cidade Nazarezinhense não é observada nenhum tipo de monitoramento ambiental, tendo em vista que se tratar de um vazadouro a céu aberto em que não há preocupação com a disposição final dos resíduos produzidos, o que avalia este indicador como DESFAVORÁVEL do ponto de vista da sustentabilidade.

\section{Conclusão}

A variável estado retrata a qualidade em que se encontra o meio ambiente, envolve aspectos como qualidade do ar, do solo, dos corpos hídricos e de todo o conjunto de características que um ambiente possui. Para a dimensão estado foram selecionados nove indicadores dos quais todos foram avaliados como DESFAVORÁVEIS do ponto de vista da sustentabilidade, por não apresentarem resultados que se adéquem aos requisitos necessários para um município conciliar o desenvolvimento econômico e conservação do meio ambiente.

\section{Declaração de conflito de interesses}

Os autores declaram não haver conflito de interesses.

\section{Referências}

Barros, J. D. S.; Moreira, R. S. Indicadores de sustentabilidade: a utilização de indicadores de sustentabilidade na avaliação do gerenciamento de resíduos sólidos urbanos. Saarbrücken: NEA - Novas Edições Acadêmicas, 2017.

Batista, A. D. Meio ambiente: preservação e sustentabilidade. Revista EPeQ/Fafibe, v. 1, p. 50-54, 2009. Disponível em: 
$<$ http://www.unifafibe.com.br/revistasonline/arq uivos/revistaepeqfafibe/sumario/3/14042010143 117.pdf>. Acesso em: 01 set. 2016.

Besen, G. R. Coleta seletiva com inclusão de catadores: construção participativa de indicadores e índices de sustentabilidade. São Paulo: Faculdade de Saúde Pública/USP, 2011.

Brasil. Tribunal de Contas da União. Cartilha de licenciamento ambiental. Brasília: TCU, 2007.

CPRM - Serviço Geológico do Brasil. Diagnóstico do Município de Nazarezinho, Estado da Paraíba. Recife: Ministério de Minas e Energia, Secretaria de Geologia, Mineração e Transformação Mineral, 2005. (Projeto cadastro de Fontes de Abastecimento por Água Subterrânea). Disponível em: $<$ http://rigeo.cprm.gov.br/xmlui/bitstream/handl e/doc/16213/Rel_Nazarezinho.pdf >. Acesso em: 01 set. 2016.

Gouveia, N. Resíduos sólidos urbanos: impactos socioambientais e perspectiva de manejo sustentável com inclusão social. Ciência \& Saúde Coletiva, v. 17, n. 6, p. 1502-1510, $2012 . \quad$ https://doi.org/10.1590/S141381232012000600014

IBGE - Instituto Brasileiro de Geografia e Estatística. 2010. Disponível em: $<$ http://ibge.gov.br/cidadesat/painel/painel.php?l ang=_PT\&codmun=251000\&search=paraiba\%7 Cnazarezinho\%7Cinfograficos:-dados-geraisdo-municipio>. Acesso em: 01 set. 2016.

Locasto, J. K.; Angelis, B. L. D. Barreiras de impermeabilização: configurações aplicadas em aterros sanitários. Revista Eletrônica em Gestão, Educação e Tecnologia $\begin{array}{llll}\text { Ambiental, } & \text { v. 20, } & \text { n. 1, } 2016 .\end{array}$ https://doi.org/10.5902/2236117020084

Lopes, L. Gestão e gerenciamento integrados dos resíduos sólidos urbanos: alternativas para pequenos municípios. São Paulo: Universidade de São Paulo, 2016. (Dissertação).
Malheiros, T. F.; Coutinho, S. M. V.; Philippi Jr., A. Desafios do uso de indicadores na avaliação da sustentabilidade. In: Malheiros, T. F.; Coutinho, S. M. V.; Philippi Jr., A. Indicadores de sustentabilidade e gestão ambiental. São Paulo: Manole, 2012.

Moreira, R. S.; Barros, J. D. S. Indicadores de sustentabilidade: a utilização de indicadores de sustentabilidade na avaliação do gerenciamento de resíduos sólidos urbanos. Saarbrücken: Novas Edições Acadêmicas, 2017.

Silva, E. L.; Menezes, E. M. Metodologia da pesquisa e elaboração de dissertação. Florianópolis: UFSC, 2005.

Silva, M. E.; Cândido, G. A. A análise de indicadores de sustentabilidade na problemática de resíduos sólidos em Campina Grande-PB. Reuna, v. 17, n. 1, p. 91-110, 2012. <http://revistas.una.br/index.php/reuna/article/vi ew/432/480>. Acesso em: 01 set. 2016.

Silva, M. E.; Cândido, G. A.; Ramalho, A. M. C. Diagnóstico situacional dos resíduos sólidos urbanos no Município de Cuité-PB: uma aplicação do Sistema de Indicador de Sustentabilidade Pressão-Estado-Impacto-Resposta (P-E-I-R). Revista Gestão Industrial, $\quad$ v. 8, $\quad$ n. 3, $\quad$ p. 72-90, 2012. https://doi.org/10.3895/S1808-04482012000300003

Silva, S. S. F. Diagnóstico situacional dos resíduos sólidos urbanos no Município de Cuité-PB, através da aplicação do Sistema de Indicador de Sustentabilidade PressãoEstado-Impacto-Resposta (P-E-I-R). Campina Grande: Universidade Federal de Campina Grande, 2010. (Dissertação). 
Rev. Bras. Gest. Amb. Sustent., 2017, v. 4, n. 8, p. 255-262. 